by one on ecological barriers, which are scarcely mentioned.

Yet though too many minor topics have been chosen, some important major ones are omitted. The ecology of marine and estuarine animals and communities, and the methods of studying them, are insufficiently described, while the vast contributions of ecology to the study of evolution are relegated to three pages. The theory of Sewell Wright is said to fall outside the scope of the book, though it is not clear why. It is mentioned in two brief paragraphs, in which it is said that "the existence of small isolated populations provides unusual opportunities for the rapid evolution of new sub-species bearing characteristics which would not be tolerated in the more normal conditions of larger populations among which natural selection is in full operation". It should also be pointed out that such conditions provide unusual opportunities for solution by natural selection. No attempt is made to include the great subject of ecological genetics, though we are told ( $p .13$ ) that "the genetic structure of a population in the wild is constantly changing, for it is the result of an equilibrium between mutation rate of recessive factors and selective elimination of unsuccessful individuals". It is very surprising that such a statement, overlooking polygenic variation and polymorphism, could be made in a modern book.

The captions on Plate 2 are interchanged, as are the two lower captions on Plates 5 and 6 . The price seems high for a book of moderate size containing eleven tables, nineteen text figures, six black-andwhite, and no coloured, plates.

E. B. FORD

\section{STUDY OF EARTHQUAKES}

\section{Elementary Seismology}

By Charles F. Richter. Pp. viii +768. (San Francisco, Calif. : W. H. Freeman and Company; London : Bailey Bros. and Swinfen, Ltd., 1958.) 12 dollars.

A $\mathbf{T}$ the present time, when geophysical methods $A$ and theories are permeating every branch of geology and geotectonics and effecting a gradual revolution in geological thinking, the appearance of a book which helps this process is an important event. Sound reasoning, likewise, in geophysics can only stem from a sound well-balanced basic knowledge of classical geology, physics and mathematics, ably synthesized as in the book under review.

This book is divided into three parts. Part 1 , entitled "The Nature and Observation of Earthquakes", contains twenty-four chapters on 394 pages. The first fourteen chapters largely concern field observations of earthquake effects, the background for these chapters being geological and non-mathematical. Chapter 15 contains an elementary discussion of seismograph theory and practice, and there follow chapters on elastic waves, deep-focus earthquakes, and the reduction of instrumental observations. The final two chapters are on microseisms and on earthquake risk and protective measures to be taken in areas likely to be subjected to earthquakes.

Part 2 of the book is entitled "The Geography and Geology of Earthquakes" and contains nine chapters on 246 pages. The author of the book for many years has taken a very great interest in this work, and being thus exceptionally well qualified for the writing, cannot fail to be informative and stimulating. After an introductory chapter he sets off immediately into a discussion of arc and block tectonics, and follows this up with descriptions of the geotectonics and earthquake phenomena of California, New Zealand, Japan and Formosa. Most of these regions have been studied at first hand in the field by Dr. Richter, as also through the medium of instrumental data and literature. The part ends with chapters on the tectonic earthquakes of other regions ; compressions and dilations; and on seismology in the U.S.S.R. Since the days of Prince B. Galitzin, Russia has been renowned for her students of seismology, and her sons to-day are worthy successors of this heritage (the late Dr. G. A. Gamburtsev; and Dr. E. T. Savarensky, Dr. D. P. Kirnos, Dr. V. I. Keylis-Borok, Dr. E. W. Karus and others).

Part 3 of the book, which contains seventeen appendixes on 100 pages, and is somewhat more advanced than Parts 1 and 2, being mostly composed of items useful in a seismological laboratory such as a list of seismological observatories, a table, of angles of incidence of elastic waves in the Earth and related quantities for shallow-focus earthquakes; the refraction and reflexion of earthquake waves including the Zoeppritz equations; transit-time tables and magnitude charts. In addition, there are items frequently requested by the general public such as lists of large earthquakes, a chronology of historically important events and discoveries in seismology ; and an appendix on earthquake-resistant construction.

As will be seen from the foregoing statements, the book is exceptionally well balanced, the proper weight having been given to field observations and geology. Within the limits set by the author it is comprehensive and even encyclopædic in its contents, being a masterpiece of selection and compression as only a practical seismologist and lively, experienced teacher could have accomplished. Since the book is so up-to-the-minute in its contents, however, one might have liked to see reference to recent experimental work on seismographs such as is being conducted at Stuttgart, Zürich and elsewhere-though perhaps the author includes this work in the list (on p. iv) of material abbreviated. However, there are very good lists of selected references by which anyone interested may pursue the studies so well begun.

The author, Prof. Charles F. Richter, is professor of seismology in the California Institute of Technology in Pasadena, California, where he has also worked for many years in the seismological laboratory with Prof. B. Gutenberg, Dr. H. Benioff and others. He is joint author with Dr. Gutenberg of the book entitled "The Seismicity of the Earth", and is an originator of the instrumental earthquake magnitude scale. For many years also Prof. Richter has been responsible for regular bulletins on local and distant earthquakes.

This book developed from a lecture course organized particularly for students of geology who do not intend to specialize in seismology or geophysics. Every geological library, and every geological student who can afford it, should get a copy of this book most opportunely published during the International Geophysical Year. It is lavishly illustrated and produced, and the printing, format and binding are all of the highest quality. The book is recommended not only to students of geology, but also to engineers and engineering students, applied mathematicians as a source book of data and ideas for problems, and to all others interested in seismology and the physics of the Earth.
ERnest Tillotson 